\title{
The Enlightenment of the current situation of China's electronic commerce to Russia
}

\author{
Gui yang \\ Liaoning Jianzhu Vocational College ,111000 Liaoyang ,Liaoning , China \\ Email: gsgldzsw@126.com
}

Keywords: Enlightenment, Development, Electronic commerce

\begin{abstract}
The twenty-first Century is the era of information technology, the third industry in countries continues to increase, especially in the service industry, information service industry has become the leading industry in twenty-first Century, which led to the emergence and development of e-commerce, the impact of the global informatization under the e-commerce represent the general trend, in the continuous improvement and perfection, e-commerce has become the focus of each country and each big company for. How to conform to the trend of world economic development, combined with national conditions, and actively and steadily accelerating the construction of electronic commerce, is an urgent need to put in front of us to solve the problem, especially the development of a more open strategy in joining W TO, under the condition of this problem is more important. Through the analysis of the problems existing in the development of China's electronic commerce in Russia, this paper puts forward the corresponding countermeasures, so as to enlighten the development of the Russian electronic commerce.
\end{abstract}

\section{Introduction}

\subsection{An overview of e-commerce}

E-commerce is an information network technology as a means of commodity exchange as the center of business activities; It can also be understood to be in the Internet (Internet), Enterprise Intranet (Intranet) and Value Added network (van,value Added Network) The activities of trading activities and related services by means of electronic transactions are the electronic, networked and informational aspects of traditional commercial activities ${ }^{[1]}$.

E-commerce usually refers to a wide range of commercial trade activities around the world, in the Internet Open Network environment, based on browser/server applications, buyers and sellers do not meet a variety of business activities, to achieve consumer online shopping, merchants online transactions and online electronic payment and a variety of business activities, trading activities, A new business operation model for financial activities and related integrated service activities. Many different definitions are given by governments, academics and business people in terms of their position and the degree of participation in E-commerce. E-commerce is divided into: ABC, business-to-business, Business-to-consumer, c2c, B2M, m2c, b2a (i.e. b2g), c2a (i.e. c2g), O2O, etc.

At the same time, network marketing is also a product of E-commerce, and for network marketing, before doing a good network marketing program, so that the implementation of the $\operatorname{plan}^{[2]}$.

\subsection{The definition of E-commerce}

E-commerce is the use of micro-computer technology and network communication technology for business activities. Many different definitions are given by governments, academics and business people in terms of their position and the degree of participation in E-commerce. However, electronic commerce is not equivalent to the electronic Business of commerce ${ }^{[3]}$.

E-commerce even in different countries or areas have different definitions, but its key is still relying on electronic equipment and network technology business model, with the rapid 
development of E-commerce, it has not only included the main content of its shopping, but also include logistics and distribution services. E-commerce includes electronic currency exchange, supply chain management, electronic trading market, network marketing, online transaction processing, electronic data Interchange (EDI), inventory management and automatic data collection systems. In the process, the information technologies used include: Internet, extranet, e-mail, databases, electronic catalogues and mobile phones ${ }^{[4]}$.

First of all, E-commerce is divided into broad and narrow sense of e-commerce. The broad sense of e-commerce is defined as the use of various electronic tools to engage in business activities; Whether in the broad sense or narrow sense of the concept of E-commerce, E-commerce covers two aspects: one is inseparable from the Internet platform, no network, it is not known as E-commerce; the second is a business through the Internet ${ }^{[5]}$.

\subsection{The development trend of e-commerce}

1) The broader environment: people are not restricted by time, not restricted by space, and are not limited by traditional shopping, and can be traded on the Internet anytime and anywhere.

2) A broader market: the world will become smaller on the Internet, a business can face the global consumers, and a consumer can go shopping anywhere in the world.

3) More rapid circulation and low price: e-commerce reduces the intermediate links of commodity circulation, saves a lot of expenses, and greatly reduces the cost of commodity circulation and transaction.

4) More in line with the requirements of the times: Nowadays people are increasingly pursuing fashion, personality and shopping environment. Online shopping can better reflect the personalized shopping process.

\section{Development of Russian e-commerce}

\subsection{The number of Internet users tends to stabilize}

According to the www.shopolog.ru website, January 27, the Russian Internet users reached the highest in 2016, accounting for 70.4\%, but it was in line with the 2015 index, not growth. According to expert analysis, the Russian internet users will usher in the future of the rational regression stage, the purchase of goods will become more practical ${ }^{[6]}$.

\subsection{Online shopping products have increased and dropped}

According to the data provided by Yandex.Market in the Russian e-commerce market information in February 2nd, online shopping products have increased and reduced.

Table 1 list of items for the first five categories of goods

\begin{tabular}{|c|c|c|c|}
\hline Category & $\begin{array}{c}\text { Increase } \\
\text { percentage points }\end{array}$ & Category & $\begin{array}{c}\text { Increase } \\
\text { percentage points }\end{array}$ \\
\hline $\begin{array}{c}\text { Upholstered } \\
\text { furniture }\end{array}$ & $19 \%$ & Bathhouse & $16 \%$ \\
\hline Digital camera & $18 \%$ & Basketball & $15 \%$ \\
\hline $\begin{array}{c}\text { Smart watches and } \\
\text { bracelets }\end{array}$ & $18 \%$ & $\begin{array}{c}\text { A sink, a wash } \\
\text { basin }\end{array}$ & $14 \%$ \\
\hline Parts & $17 \%$ & $\begin{array}{c}\text { A toilet, a pooling } \\
\text { pool, a bathtub }\end{array}$ & $13 \%$ \\
\hline $\begin{array}{c}\text { TV and plasma } \\
\text { panel }\end{array}$ & $15 \%$ & Skate & $-10 \%$ \\
\hline
\end{tabular}

\subsection{Cross-border electricity sales of products increased year by year}

According to the "Industrial St. Petersburg," reported that the Russian 2016 years ago, the three quarter of the shop sales record record high, reached 48 million orders, compared to the same 
period in 2015 21\%, the Russian "data perspective" company data show that in 2015, Russian consumers in the overseas Electric Dealer website orders (only the kind of consumer trade 80 million, an increase of $75 \%$. The total number of cross-border electrical business parcels amounted to 130 million. Across the border, the total consumption amounted to 160 billion rubles, an increase of $88 \%$. Compared with 2014, the proportion of the total number of Cross-border electricity orders in the 2015 was increased from 24\% to 34\%, and the proportion of Cross-border electricity trade in the total amount of Russian electric commerce was up from 13\% to 20\%. According to expert analysis, although the Russian electronic commerce is affected by the economic crisis, but still maintain accelerated growth momentum, the Russian residents in the domestic platform net purchase amount slightly more than in the foreign shop purchases. China's Alibaba-owned global fast-selling platform has grown rapidly in Russia, and the number of people using the platform is on the rise in particular in remote parts of Russia ${ }^{[7]}$.

\subsection{Online payment methods commonly used in internet shopping}

According to the tripod pay Gleepay researchers, in the choice of payment methods, Russian consumers still prefer the bank card, the use rate as high as $76 \%$. In contrast, the use of Yandex. Payment of electronic wallet accounted for 56\%, the use of WebMoney electronic wallet accounted for $47 \%$, the use of QIWI electronic wallet accounted for 45\%, the use of Paypal electronic wallet accounted for $13 \%$, the use of RBK money electronic wallet accounted for $3 \%$. From the popularity level, WebMoney is Russia's most popular third-party payment tool, followed by Yandex. Money, Qiwi, RBK money and Robokassa. In addition, there are some relatively small payment methods such as Payu, Payonline and Moneymail ${ }^{[8]}$.

\subsection{The Russian government has been increasing its policy support}

In February 2016, the Russian Ministry of Economic Development proposed at the government interdepartmental working conference that the Russian government could return part of its profits tax to small and medium sized exporters who sell their goods through the Russian electric platform. In addition, the Department also intends to consult with Customs and other departments, to simplify the Russian enterprises through the Electronic Business platform for export clearance procedures, and further promote the platform of electronic business to promote SME products exports; December 2016, the European-Asian Economic Union countries cross border E-commerce tax exemption starting point will gradually reduce. The Eurasian Intergovernmental Committee has instructed the Eurasian Economic Commission to reduce the duty-free trade threshold to $€ 500$ a month after the implementation of the Customs Code (2018), which would exceed $30 \%$ per cent of the total threshold, but not less than 4 euros for each kilogram. Two years after the implementation of the Customs Code (2019) The duty-free trade threshold should be reduced to 200 euros, and the tariffs exceeding this standard would be $15 \%$ of the total threshold, but not less than 2 euros per kilogram. The information service of the Eurasian Economic Commission confirmed this message and noted that the drafting of the law on reducing duty-free online trade thresholds would commence after the signing of the European-Asian Economic Union Customs Code Treaty, which was to be signed at the end of December. The Russian Treasury expects the Customs Code to come into effect in the middle of 2017. At present, duty-free e-commerce threshold of 1000 euros $^{[9]}$.

\section{Sino-Russian Cross-border e-commerce development}

\subsection{Basic situation of Sino-Russian trade}

2012 years of Sino-Russian trade volume to record a new record, reached 88.16 billion U.S. dollars, up from the previous year $11.2 \%$. China's exports to Russia rose $13.4 \%$, rising $9.9 \%$ from Russia. 2013 has been very likely to break the 100 billion dollar mark, 2020 years ago to reach 200 billion dollars. At present, Russia's Sino-Russian joint ventures reached more than 1000, only in Russia's Far East area registered in the Sino-Russian joint venture has reached more than 600, compared with the total number of Russian joint ventures $40 \%$. There are already 750 Chinese and 
Russian joint ventures in China, mainly in the northern and northeastern parts of China bordering Russia.

In Sino-Russian economic and trade cooperation, the frontier trade is becoming more and more important. Sino-Russian border trade accounted for about $20 \%$ of the total Sino-Russian trading, accounting for $43 \%$ of China's overall external trade volume. The cooperation environment and conditions in the two countries ' border areas are improving, exchanges are quicker and trade and investment are more convenient. Heihe, Suifenhe, Tongjiang and other ports have developed rapidly, the completion of the construction of Sino-Russian trade complex will help push forward the further development of the border trade ${ }^{[10]}$.

\subsection{The problems existing in Sino Russian trade and cross-border e-commerce}

One is that the two countries have a lower level of trade. Sino Russian trade is expected to be close to $\$ 100$ billion this year, equivalent to the target of China's trade with Vietnam. The trade structure of the two sides is also relatively simple. According to customs statistics, China's export to Russia is dominated by labor intensive industries. Vegetable oil, food and beverage products exports accounted for eighty of total exports Chinese percent; imports from Russia to resource intensive, timber, pulp and chemical products accounted for seventy percent of total imports, mechanical and electrical products, high-tech, high value-added products the proportion is not high, the level of trade between the two sides low, restricts the development of the trade scale. The two is that the bilateral trade system is not perfect, and the trade order needs further standardization. According to international practice, China's trade system with Russia, such as bank settlement, legal arbitration, quality supervision and customs clearance, is not perfect enough. In the actual operation of China's trade with Russia, there are still some negative phenomena, such as low contract performance, debt default, intentional detainment of goods and capital, charter tax and so on. In particular, the existence of "gray clearance" phenomenon makes it difficult for Chinese goods to enter the Russian market through charter flights and other channels to get effective customs clearance certificates. The three is that the information channel is blocked and the amount of information is insufficient. Due to the lack of official government information channels and authoritative information intermediary agencies to provide information about the Russian enterprises to the current market conditions, investment environment, government policies, industrial production and technology development status information, the influence between the two companies to establish the direct relationship between the economic cooperation. China and Russia should strengthen the construction of the economic and trade relations information system. Four, the problems existing in the policy of the Russian side also restrict the development of trade between the two countries. Russia imports to set high tariff barriers, especially commodity imports from China, such as textiles, shoes, leather etc.. Russian tariffs from the amount of ad valorem tax tax, and mixed in three forms, the Russian customs in the collection are not required, but have been assessed by high taxes, such as imports of leather, if required to be at a rate of twenty half of the price of the ad valorem tax, but often follow from the amount of tax levy, Chinese enterprises greatly increased the amount of tax, equivalent to two hundred percent of the ad valorem tax. The Russian management policy is not uniform, unstandardized and opaque. With our country bordering mainly Russia's East Siberia, West Siberia and the Far East, including Altai, Chita, coastal border, Amur Oblast, Jewish Autonomous Prefecture and Khabarovsk border region, 6 federal subjects, these states implementation is not consistent in the foreign trade policy, which led directly to the two countries in the border trade barriers the heavy. Besides, Russia's economic and trade policies are very opaque. Chinese enterprises can only learn about the tax and management policies of certain commodities from trade practice, but they can not know about other commodities. Russia's policy is changeable. Once the policy is changed, enterprises are often caught out of hand and bring difficulties to normal economic and trade activities. The five is that the logistics channels of China and Russia are not smooth. Customs supervision is difficult for traditional logistics channels, and customs declaration can not be done. Most of them take the way of gray customs clearance, so the entry goods have no legal status, and the security is not guaranteed. Russian customs lack of cross-border e-commerce 
settlement mechanisms and programs, resulting in a large number of packages overloaded at customs, the processing time is 40-80 days, and even a large number of goods often lose. The Russian postal system has low processing power and lazy attitude to the staff. Facing the experience of electronic commerce, such a package is not properly selected, resulting in a large backlog of goods. DHL, UPS, EMS and other large international logistics enterprises cost too much, and individuals can not act as consignees. The commodity package is complex, which makes the operation cost of e-commerce greatly improved. Because most of the export goods are parcels, the electricity providers can not normally collect foreign currency, and they can't get the tax rebate. Most of the sales proceeds go back to China through grey channels, and enterprises are faced with huge legal risks ${ }^{[11]}$.

\section{The Enlightenment of China's electronic commerce to Russia}

\subsection{China's electronic commerce blowout for the next 10 years}

China's Internet users grew from 22 million 500 thousand in 2000 to 420 million in 2010. The rapid growth of the number of Internet users has laid a solid foundation for the rapid development of electronic commerce. The volume of e-commerce transactions in China has risen sharply from 54 billion 500 million RMB in 2001 to 36000 billion yuan in 2009. In 2010, China's e-commerce trading volume is expected to reach 47000 billion.

In the past ten years, China's electronic commerce has experienced a high speed growth stage, which will show a blowout development in the next 10 years. According to the survey data of China's B2B Research Center, by June 2009, the total number of e-commerce sites above China's scale has reached 12282. Among them, there are 5320 B2B e-commerce service enterprises. B2C, C2C and other non mainstream enterprises have reached 6962. ERI predicts that China's e-commerce transaction will reach 12 trillion and 700 billion in 2013. From 2010 to 2013, the size of the e-business market will continue to maintain an annual growth rate of about $40 \%$.

China's e-commerce has gone through five stages: germination period, adjustment period, recovery period, high-speed development, and transformation and upgrading.

\subsection{Characteristics of e-commerce in China}

China's B2B e-commerce features B2B e-commerce model in China as the leading figure of the Alibaba, forming a unique situation. Before 2008, the basic growth pattern of B2B e-commerce in China was developed. The Alibaba occupies an absolute advantage within the industry, covering millions of small and medium sized enterprises in China. Other e-commerce platforms are mostly enterprise information display platforms, with a large number of but less practical trade.

Since 2008, B2B e-commerce, represented by Dunhuang network and golden and silver island, is following the trend of rapid development. These electronic, business platform not only completed the function of the display of the enterprise information flow, but also realized the unity with the three parties of logistics and cash flow. The followers of B2B e-commerce enterprises emphasize the profit and potential value, as well as the integrated application of e-commerce. Taking Dunhuang network as an example, it is developing with the core of online trade and the operation mode based on transaction commission.

At the beginning of 2009, some of China's B2B e-commerce enterprises have been competing for the market. The successful listing of China's manufacturing network has caused the B2B industry's leading e-business platform to be listed, and the industry shuffling stage has come. Gold and silver island, which pioneered the trade of B2B's bulk products online, got 100 million yuan in venture capital in June. The 66 net, which is the core of the official website of the enterprise, has also received tens of millions of dollars in financing in November.

With the rise of China's manufacturing, the focus of B2C e - commerce will slowly shift to the online trade market in the next few years. 09 years, under the influence of the financial crisis, foreign buyers orders showed small, multi frequency buy trend, which brings the development opportunity for the online trade market. Alibaba launched a small foreign trade platform aliexpress. 
HC also launched a platform called madeinchina. B2B core operators have seen the prospects for the development of the online foreign trade market.

China's B2C e-commerce features the trend of B2C e-commerce in China is basically determined by the order of entry into the market, and it can be divided into three distinct camps in a timely order. The first camp is the market leader, and its representative website is Dangdang network and network of excellence. Outstanding and Dangdang in China's electronic commerce has not yet been the initial market, the first set up. With good technology, logistics, payment, popularity and other advantages, is expected to become a strong market challenger; the second camp includes Jingdong mall, 139shop.com, new egg network, Mcglaughlin network, interactive publishing network, colorful Valley, as well as some of the products of direct selling companies, such as Dell, PPG etc.. These websites are all the leading websites in various product segments. They are in a steady growth state. The third camps are other market participants and long tail websites, such as a large number of personal or workshop B2C websites or some local B2C websites. These websites have a large number of websites, but they have limited impact on the current market share of B2C e commerce in China.

In the next 5 years, the trend of B2C e-commerce development is to solve the integration of line and line trading channels. About $80 \%$ of the people are still not online shopping, and a forward-looking e-commerce website has begun to explore how to cover the $80 \%$ people who haven't bought online shopping. At present, almost all the traditional offline businesses want to develop into online channels, and many online businesses want to develop into offline channels. This is the general trend for all enterprises to develop in the future.

\subsection{Alibaba and Taobao}

The development status and success factors of Alibaba are analyzed. After 10 years of development, Alibaba has developed into the world's leading B2B e-commerce company from the registered capital of 500 thousand yuan e-commerce company. Alibaba has three platforms of international trading market, Chinese trading market and Japanese trading market. Services are provided for import and export traders in the world, China and Japan respectively. Alibaba has formed a virtual wholesale and retail market with users covering more than 240 countries and regions and registered users over 140 million.

The Alibaba laid the foundation for its future success when China's electronic commerce was extremely immature. In 1999, Ali was in the early days of his business, and founder Ma Yun tried to publicize its own e-commerce theory and cultivate potential users in China. In 1999, there were only about 10 million Chinese Internet users, and most of them didn't know anything about e-commerce. In 1998, Ma Yun registered the e-commerce platform in the Cayman Islands. The extensive propaganda work in the early days of the business made the company get the approval of the venture company at the most difficult time of the start - up and get the two venture capital.

Alibaba relies on the current situation of global commodity manufacturing in China, and skillfully utilizes the online credit mechanism to solve the problem of how to establish trade relations with Chinese small and medium-sized companies. The status of the world's factory in China is more prominent in the new millennium. However, in the Chinese market, ERON is mixed up, so how to find trustworthy sellers in such an asymmetric information market is the key. The core product of the Alibaba is the integrity of the service, for each enterprise to establish the online integrity files, and become a fair third party evaluation platform. Unfamiliar buyers from all over the world can make a reasonable assessment of unmet businesses, depending on the records of trustworthy archives. China's Guangdong and Jiangsu and Zhejiang excellent medium and small enterprises provide a solid user base for the Alibaba.

\section{Conclusion}

To sum up, with the economic globalization and the rapid development of information technology and information industry, E-commerce will become the focus of information exchange in the future, to become the development of various countries, the most concerned areas of the 
industry. Although the Russian electronic commerce is still in the initial stage, facing the system, technology, management and many other problems, but they through the analysis of China's development of Russian e-commerce problems, so as to draw inspiration for the development of Russian E-commerce, and promote the two countries in the world of electronic commerce development common!

\section{References}

[1]Shvetsov S. Problem of Electronic Commerce in Russia: Electronic Signature[J]. 2014, 2(2):46-54.

[2]Engdahl F W. Washington's Geopolitical Nightmare: China and Russia boost economic cooperation, by F. William Engdahl[J].

[3]Wu Y. Development Status and SWOT Analysis of Cross-border E-commerce between China and Russia[J]. Foreign Economic Relations \& Trade, 2016.

[4]Fey C. Electronic commerce in Russia (Academy of International Business - AIB - Conference, San Juan Puerto Rico)[J]. 2002.

[5]Fey C, Doern R. Electronic commerce in Russia[J]. Baltic Development Forum Partnership \& Growth in the Baltic Sea Region, 2001.

[6]Shvetsov S. Problem of Electronic Commerce in Russia: Electronic Signature[J]. 2014, 2(2):46-54.

[7] Xiong Xiao. Research on the current situation of China's e-commerce and Its Countermeasures [J]. era economy and Trade: Academic Edition, 2008, 6 (21): 81-82.

[8] Su Zhenjiang. The development and Enlightenment of electronic commerce in Russia [J]. Heilongjiang finance, 2017 (7): 71-73.

[9] Zhang Xiaheng. The development path and optimization direction of Russia's cross-border e-commerce [J]. research in Eastern Europe and Central Asia in Russia, 2016 (6).

[10] Huang Wei. The Sino Russian cross-border electronic commerce development present situation and Countermeasures of foreign trade [J]., 2016 (5): 107-108.

[11] Li Yang. Russian e-commerce trade status and Sino Russian cross-border e-commerce trade cooperation [J]. Jilin Province Economic Management Cadre College Journal, 2017, 1 (5). 